\title{
An approach to identify issues affecting ERP implementation in Indian SMEs
}

\author{
Rana Basu ${ }^{1}$, Parijat Upadhyay ${ }^{2}$, Manik C. Das ${ }^{3}$, Pranab K. Dan ${ }^{1}$ \\ ${ }^{1}$ West Bengal University of Technology, ${ }^{2}$ Globsyn Business School, ${ }^{3}$ MCKV Institute of Engineering \\ (INDIA) \\ rbasu004@gmail.com; parijat.upadhyay@gmail.com; cd manik@,rediffmail.com; \\ danpk.wbut@gmail.com
}

Received October 2011

Accepted April 2012

\section{Abstract:}

Purpose: The purpose of this paper is to present the findings of a study which is based on the results of a comprehensive compilation of literature and subsequent analysis of ERP implementation success issues in context to Indian Small and Medium scale Enterprises (SME's). This paper attempts to explore the existing literature and highlight those issues on ERP implementation and further to this the researchers applied TOPSIS (Technique for order preference by similarity to ideal solution) method to prioritize issues affecting successful implementation of ERP.

Design/methodology/approach: Based on the literature review certain issues leading to successful ERP implementation have been identified and to identify key issues Pareto Analysis (80-20 Rule) have been applied. Further to extraction of key issues a survey based on TOPSIS was carried out in Indian small and medium scale enterprises.

Findings: Based on review of literature 25 issues have been identified and further Pareto analysis has been done to extract key issues which is further prioritized by applying Topsis method. 
Research limitations/implications: Beside those identified issues there may be other issues that need to be explored. There is scope to enhance this study by taking into consideration different type of industries and by extending number of respondents.

Practical implications: By identifying key issues for SMEs, managers can better prioritize issues to make implementation process smooth without disruption. ERP vendors can take inputs from this study to change their implementation approach while targeting small scale enterprises.

Originality/value: There is no published literature available which followed a similar approach in identification of the critical issues affecting ERP in small and mid-sized companies in India or in any developing economy.

Keywords: ERP, small and medium scale enterprise, Pareto analysis, Topsis, India

\section{Introduction}

Enterprise Resource Planning (ERP) system has emerged as a common and necessary platform among small and medium scale enterprises not only to remain competitive in the global business scenario but also to streamline their own internal processes to collaborate with their foreign partners in their supply chain. ERP is generally viewed as necessary infrastructure and is also a strategic weapon in automating business processes while providing visibility to those processes throughout the enterprise. Investment in enterprise information systems remains the top priority for information technology (IT) organizations, more so when organizations needs to meet regulatory compliance. At the same time, companies recognize that support and integration costs may be reduced by consolidation to fewer systems and application instances. Packaged applications, in the form of Enterprise Resource Planning (ERP) systems, consist of standard multifunctional, multi-language, multi-legislative of software modules that can offer integration across an entire organization. It has the capability to integrate far flung outposts of a company along with supply chain activities. ERP systems are complex and expensive, and the decision to install that system necessitates a choice of mechanisms for whether ERP is needed and, once implemented, whether it is successful. Numerous cases can be cited where in organizations have spent high 
amount on implementation but unable to derive benefit at all out the implementation.

Small and Medium Scale Enterprises (SMEs) are increasingly brought into focus on account of their huge growth potential and vary in magnitude, age, sector, and knowledge base with innovative capacity (Koh \& Simpson, 2007; Deep, Guttridge, Dani \& Burns, 2008; Helo, 2008). The SME sector in India contributes almost half of India's GDP and is home to slew of business opportunities. SME form the large majority of industrial and service units across the world and is a source of employment (Thomson \& Gray, 1999). India's SME sector is a vibrant, dynamic, flexible and productive entity, containing as many as some 12 million units and employing almost 30 million people. The sector quickly adapted and restructured itself to face competition from global players head-on. SME embraced high technology, accepted norms of quality and competitiveness and continued to expand faster than the rest of the industrial economy (Aberdeen, 2009; Hughes, Golden \& Powell, 2003).

Small and mid-size organizations, in particular, face a dilemma focusing on business drivers impacting Enterprise Resource Planning (ERP) strategies. A recent study finds SME companies focusing on growth strategies and customer service sometimes balancing between the two, but more often focusing exclusively on one or the other. As companies grow in size and improve performance, they are more likely to have invested in an ERP system that will grow with them. But growth cannot come at the expense of customer service. As mid-size companies grow, they must learn to operate in a distributed environment and often experience a proliferation of ERP and other enterprise applications.

Implementation of Information systems (IS) in general is quite difficult. It is therefore not surprising that implementations of ERP would be equally if not more difficult due to their size, scope and complexity. The benefits of ERP cannot be easily achieved and inconsistent outcome of the system have been reported (Hayes, Hinton \& Reck, 2001; Hitt, Wu \& Zhou, 2002; Hinton, McEwen \& Wier, 2002; Mandal \& Gunasekaran, 2002; Palaniswamy \& Frank, 2000; Vogt, 2002). The very fact that about $60-70 \%$ of all ERP implementations in organizations end up with failure (Harvard, 2007; Leung, 2008). A number of publications have highlighted the failures and the frustrations that enterprises go through in implementing ERP systems. Some notable failures are Dell, Fox-Meyer and Hershley. A Gartner group study was carried out in 1300 European and American companies and found that $32 \%$ of ERP projects were delivered late and thus unable 
to reap benefits of implementation. As cases of ERP failures have increased, many studies have been initiated to identify factors that could lead to ERP implementation success. This paper tries to identify certain factors that can be considered critical in context to SME's on account of their peculiarities (Moshabbaki, 2009; Chen, 2008) with focus on Indian SMEs.

\section{Literature review}

ERP system implementation issues have been subjected to ample research under various theoretical perspectives dealing with aspects like: attribute, adoption and implementation process (Nandhakumar, Talvinen \& Rossi, 2004; Butler \& Pyke, 2003), project design or accomplishment (Laframboise, 2002), organizational influence (Westrup \& Knight, 2000), predicting the probability of success (Magnusson, Nilsson \& Carlsson, 2004), advancement towards e-commerce (Schubert \& Leimstoll, 2004; Kemppainen, 2004; Schubert, 2003). For developing countries like India ERP system is in its early stage. It has been found that reasons like limit of capital, non-availability of resources, poor management base, and dearth of IT expertise are seriously affecting the implementation and adaptation of enterprise system in India and other similar Asian developing countries compared to the developed countries. SMEs either do not have sufficient resources or are not willing to commit significant portion of resources to complex ERP implementation process (Buonanno, Faverio, Pigni, Ravarini, Sciuto \& Tagliavini, 2005), SMEs are more fragile than large companies (Rao, 2000), and the adoption of ERP is no longer limited to large scale enterprises (Loh \& Koh, 2004). According to a previous researcher (Huin, 2004) unless the differences between SME and large enterprises are clearly conceived, the ERP project may not be able to ensure a positive outcome. So, deeper understanding of ERP implementation in SMEs needs to ensure a strong impact. Those fact holds that SME niche definitely require specific research and analysis other than previous investigations primarily targeting larger enterprises. This need has been understood so some researchers have started addressing specifically ERP implementation at SMEs. In this section some similar developing countries like India are selected to understand the characteristics of ERP in those countries and to investigate the issues that are affecting the implementation of ERP system. 


\subsection{Review of Literature of ERP implementation issues in Small and Medium Scale Enterprise (SME):}

Several academics and practitioners have tried to capture the main reasons for failure or success of ERP implementations (Ewusi-Mensah, 1997; Stapleton \& Rezak, 2004; Weightman, 2004; Anexinet, 2006; Kimberling, 2006; Ibrahim, Sharp \& Syntetos, 2008; Lindley, Topping \& Lindley, 2008). Most of these analyses focus on the issues that contributed to failures than those contributed to success. If all these factors are controlled and managed so that they are phrased as positive factors that contribute to success and the factors that appeared mostly on the lists include: Top level management support, User training and education, Project management, clearly defined goals and objectives, Project team competence, and Change management(Upadhyay \& Dan, 2008, 2009).

SMEs either do not have sufficient resources or are not willing to commit a substantial portion of their resources, due to implementation time being longer (Proudlock, 1999) and high fees associated with it (Chan, 1999). So cost of package can also be taken as crucial issue towards successful implementation of ER The compatibility of technology and company's need must be carefully addressed as ERP project involves a complex transition from legacy information systems and business processes to an integrated IT infrastructure (Al-Mashari, AlMudimigh \& Zairi, 2003).

In a research study after reviewing 28 articles identified ten success factors or issues in implementing ERP system in Malaysian companies which are: Support from top management, Clear goals and objectives, Communication, Effective project management, Business process engineering, Data accuracy and integrity, Suitability of software and hardware, Support from vendor, Education and training and User involvement (Jafari et al., 2006).

In case of small and medium scale enterprises of India a study conducted by researchers for ensuring successful implementation of ERP six major factors have been identified that includes: clarity in goals and objectives behind implementation, adequate user training, competent project implementation team, acceptance of change brought about by implementation, proper vendor support, participation of external consultant (Upadhyay \& Dan, 2008). Further to this the researchers in context to implementation of IT projects revealed seven factors that have been found to be crucial that are: Top management support, properly defined goals and objectives, user knowledge, project champion, project team competency, improve work efficiency, scalability \& scope and ERP importance (Upadhyay \& Dan, 2009). 
Proper package selection plays a crucial role in successful implementation of ER Normally the organization selects a package which is most users friendly, has adequate scope for scalability and covers an array of business processes where organization experiences problem. The selection of the specific ERP package is one that requires careful attention (Kraemmergaard \& Rose, 2002; Yusuf, Gunasekaran \& Wu, 2006; Al-Mashari et al., 2003; Somers \& Nelson, 2001, 2004).

In a research study by two researchers ten success issues have been identified by analyzing ten selective articles which are: ERP teamwork and composition, Top management support, Business plan and vision, Effective communication, Project management, Appropriate business and legacy system, Software development, Testing and troubleshooting, Effective - decision making, Effective training (Nah \& Lau, 2001).

Umble, Haft and Umble (2003) summarized the literatures and listed the nine critical factors towards successful implementation of ER Those includes: clear understanding of goals, support from top management, project management, change management, data accuracy, proper education and training, focused performance measures and multi-site issues.

Through a semi structured interview of the experts involved in the implementation of ERP in a major Chinese enterprise, the researchers presented six critical success factors that include: Commitment from top management, project team, proper project management, process change, proper education and training and effective communication (Woo, 2007).

\section{Methodology and research objective}

Based on the literature review certain issues and factors leading to successful ERP implementation have been identified. On the basis of frequency of citations made by authors in ERP implementation issues in context to small scale enterprises of similar developing countries like India 25 issues have been identified. In order to identify key issues Pareto Analysis (80-20 Rule) have been applied. For this purpose, each issues mentioned by authors at least once in the literature are listed down with the frequency of each issues. From the frequency calculated for each issue the percentage contribution of each issue is computed, and the cumulative percentage contribution of issues also calculated. It has been found that only 8 issues out of 25 are contributing $80 \%$ of the total percentage contribution (See Table 1). Hence, those 8 issues are regarded as the key issues being extracted from the review section in context to ERP implementation in SME's of developing 
countries like India and on the basis of those key issues questionnaire was made for further analysis. Further to extraction of key issues a survey based on TOPSIS was carried out in Indian small and medium scale enterprises.

\begin{tabular}{|l|r|r|r|}
\hline $\begin{array}{l}\text { Issues mentioned in the } \\
\text { literature }\end{array}$ & $\begin{array}{c}\text { Number of } \\
\text { instances cited in } \\
\text { the literature }\end{array}$ & $\begin{array}{c}\text { Percentage } \\
\text { contribution of } \\
\text { each issue }\end{array}$ & $\begin{array}{c}\text { Cumulative } \\
\text { percentage of } \\
\text { issues }\end{array}$ \\
\hline Education \& training & 13 & $13.82 \%$ & $13.82 \%$ \\
\hline Top management support & 12 & $12.76 \%$ & $26.58 \%$ \\
\hline $\begin{array}{l}\text { Properly defined goals \& } \\
\text { objectives }\end{array}$ & $11.70 \%$ & $38.28 \%$ \\
\hline Competent project team & 11 & $11.70 \%$ & $49.98 \%$ \\
\hline Project management & 10 & $10.63 \%$ & $60.61 \%$ \\
\hline Change management & 10 & $10.63 \%$ & $71.24 \%$ \\
\hline Proper package selection & 5 & $5.31 \%$ & $76.55 \%$ \\
\hline Effective communication & 3 & $3.19 \%$ & $81.86 \%$ \\
\hline Vendor support & 2 & $2.12 \%$ & $83.98 \%$ \\
\hline Data accuracy & 2 & $2.12 \%$ & $85.04 \%$ \\
\hline User knowledge & 1 & $1.06 \%$ & $86.10 \%$ \\
\hline External consultant & 1 & $1.06 \%$ & $87.16 \%$ \\
\hline Improved work efficiency & 1 & $1.06 \%$ & $88.22 \%$ \\
\hline IT infrastructure & 1 & $1.06 \%$ & $89.28 \%$ \\
\hline Cost of package & 1 & $1.06 \%$ & $90.34 \%$ \\
\hline Scalability and scope & 1 & $1.06 \%$ & $91.40 \%$ \\
\hline S/W Development & 1 & $1.06 \%$ & $92.46 \%$ \\
\hline Testing and & 1 & $1.06 \%$ & $93.52 \%$ \\
\hline troubleshooting & 1 & $1.06 \%$ & $94.58 \%$ \\
\hline Effective decision making & 1 & $1.06 \%$ & $95.64 \%$ \\
\hline BPR & 1 & $1.06 \%$ & $96.70 \%$ \\
\hline Performance measure & 1 & $1.06 \%$ & $97.76 \%$ \\
\hline User invement & 1 & $1.06 \%$ & $99.82 \%$ \\
\hline Suitability of h/w \& s/w & $1.06 \%$ & $100 \%(a p p r o x)$ \\
\hline ERP importance & 1 & $100 \%(a p p r o x)$ & \\
\hline Multisite issues & 1 & & \\
\hline Total & 1 & $1.06 \%$ & \\
\hline
\end{tabular}

Table 1. Pareto analysis (80-20 Rule)

The issues for successful implementation of ERP after extracting from Pareto analysis can be listed as follows: education \& training ( $A 1)$, support from top management (A2), Properly defined goals \& objective (A3), project team competence (A4), project management (A5), change management (A6), proper selection of package (A7) and effective communication (A8). Also the most important benefit criteria that appeared frequently in the literature (Shang \& Seddon, 2002), and from the targeted organizations objective in implementing ERP projects have taken into account for analysis, those are: efficiency in overall business (C1), improved decision making and planning (C2), better utilization of resource (C3), organizational empowerment (C4), improvement in productivity and quality (C5). The basic aim of this paper is to identify the most important issues that would actually lead to successful ERP implementation and to prioritize the issues against the benefit criteria by applying TOPSIS (Technique for order preference by similarity to ideal solution) method. 


\subsection{Survey methodology}

A questionnaire was framed based on the 8 issues obtained after doing Pareto analysis. A survey based on Topsis was carried out in Indian industries and responses of expert opinion have been taken. All such organizations are SME in nature and are reaping the same benefits as mentioned earlier. Invitations to participate in the survey requested responses from implementers of ERP packages who have basically worked for SME's based in India. The responses of the end users working in the organizations where ERP systems have been implemented were also taken. In this study the researchers made the questionnaire based on 9-point scale where 1 meant strongly disagreed and 9 meant extremely agreed. On the basis of questionnaire survey the issues were given weightage with respect to benefit criteria as well as the respondents were asked to give weight age to the benefit criteria's. (See Table 2)

\subsection{Data collection procedures}

The first part of data collection phase involved the literature review and exhaustive search of many of the prime Management Information System (MIS) journals including that the researchers could access, but not limited to those that include: Journal of Information Systems, Journal of Management Information Systems, International Journal of Production Economics, Journal of Small Business \& Enterprise Development, Journal of Enterprise Information Management, International Journal of Production Economics, Business Process Management journal, Communications of the ACM, IEEE journal etc. In addition to, the preceding journals, some conference papers were also accessed as well as the following databases were searched like Emerald, Science Direct, Proquest, Ebscohost, Springer, J Stor etc.

The second part of data collection phase involved the questionnaire survey and expert views and rating from various industries which are SME in nature. The target respondent in each firm were the EDP manager, Chief operating officer, and other person who are directly involved in ERP system. Overall 50+ responses from different organizations were obtained for analysis. Multiple responses were allowed from an organization. Because the survey questionnaire were also distributed by the vendor officials to the members of their respective user lists through e-mails, it was not possible to determine the number of recipients and the response rate. It was deliberate attempt on the part of the researcher not to collect any response in his presence so as to minimize the chance of any biasness. 


\subsection{Evaluation of importance of criteria}

The evaluators (Expert opinion having expertise in the field of ERP) estimated the weights for each criterion using their subjective judgment. Five evaluators were taken for this purpose. As seen in the Table 2, the Evaluator 1 (E1) assigned weights of $2,3,2,1$, and 2 to the five criteria respectively. The sum of the weight is $(2+3+2+1+2) 10$, and is common to all evaluators. The averages obtained for each criterion are given in the table 2 .

\begin{tabular}{|c|r|r|r|r|r|r|}
\hline \multirow{2}{*}{ Evaluator } & \multicolumn{7}{|c|}{ Criterion } \\
\cline { 2 - 7 } & C 1 & C 2 & C 3 & C 4 & C 5 & \multicolumn{1}{l|}{ Sum } \\
\hline E1 & 2 & 3 & 2 & 1 & 2 & 10 \\
E2 & 4 & 2 & 1 & 2 & 1 & 10 \\
E3 & 2 & 1 & 1 & 1 & 5 & 10 \\
E4 & 3 & 2 & 2 & 1 & 2 & 10 \\
E5 & 4 & 1 & 1 & 1 & 3 & 10 \\
\hline Average & 3 & 1.8 & 1.4 & 1.2 & 2.6 & \\
\cline { 1 - 5 } & & &
\end{tabular}

Table 2. Average per criterion

\subsection{Topsis method}

The TOPSIS (technique for order preference by similarity to ideal solution) was first introduced by the researchers (Hwang \& Yoon, 1981). This technique suggests that the best alternative would be the one that is nearest to the positive-ideal solution and farthest from the negative ideal solution (Ertugrul \& Karakasoglu, 2007). The positive-ideal solution is a solution that maximizes the benefit criteria and minimizes the cost criteria, whereas the negative ideal solution maximizes the cost criteria and minimizes the benefit criteria (Wang \& Elhag, 2006). In brief, the positive-ideal solution is composed of all best values attainable from the criteria, whereas the negative ideal solution consists of all worst values attainable from the criteria. The general steps of the TOPSIS method are as follows.

Step 1. A decision matrix is formed and expressed as follows.

$$
\begin{aligned}
& \begin{array}{lllllll}
F_{1} & F_{2} & \ldots & F_{j} & \ldots & F_{n}
\end{array} \\
& \mathrm{D}=\begin{array}{c}
A_{1} \\
A_{2} \\
. . \\
A_{i} \\
. . \\
. . \\
A_{m} \\
.
\end{array}\left[\begin{array}{cccccc}
\theta_{11} & \theta_{12} & . . & \theta_{1 j} & . . & \theta_{1 n} \\
\theta_{21} & \theta_{22} & . . & \theta_{2 j} & . . & \theta_{2 n} \\
. . & . . & . . & . . & . . & . . \\
\ddot{\theta_{i 1}} & \ddot{\theta_{i 2}} & . . & \ddot{\theta}_{i j} & . . & . . \\
. . & . . & . . & . . & . . & . . \\
\ddot{\theta}_{m 1} & \ddot{\theta_{m 2}} & . . & \ddot{\theta}_{m j} & . . & \ddot{\theta}_{m n}
\end{array}\right]
\end{aligned}
$$


Where $A_{i}$ represents the alternatives, $i=1,2, \ldots, m ; F_{j}$ represents $j$ th attribute or criterion, $j=1,2, \ldots ., n$, related to $i$ th alternative; and $\Phi_{i j}$ indicates the performance rating of each alternative $A i$ with respect to each criterion $F_{j}$.

Step 2. Calculate the normalized decision matrix $R=\left[r_{i j}\right]$. The normalized value $r_{i j}$ is calculated as:

$$
r_{i i}=\frac{\theta_{i j}}{\sqrt{\sum_{i=1}^{m} \theta_{i j}^{2}}} ; \quad j=1,2, . n ;
$$

Step 3. Calculate the weighted normalized decision matrix by multiplying the normalized decision matrix by its associated weights. The weighted normalized value $V_{i j}$ is calculated as:

$V_{i j}=w_{j} \times r_{i j} ; \quad i=1,2 \ldots m$ and $j=1,2 \ldots n$;

Where $w_{j}$ represents the weight of the $j$ th attribute or criterion.

Step 4. Determine the positive-ideal and negative-ideal solutions.

$$
\begin{aligned}
& \mathrm{A}^{+}=\left\{V_{1}^{+}, V_{2}^{+}, \ldots \ldots \ldots V_{n}^{+}\right\}=\left\{\left(\operatorname{Max}_{i} V_{i j} \mid j \in K\right),\left(\operatorname{Min}_{i} V_{i j} \mid j \in K^{\prime}\right) i=1,2, \ldots m\right\} \\
& \mathrm{A}^{-}=\left\{V_{1}^{-}, V_{2}^{-}, \ldots \ldots . V_{n}^{-}\right\}=\left\{\left(\operatorname{Min}_{i} V_{i j} \mid j \in K\right),\left(\operatorname{Max}_{i} V_{i j} \mid j \in K^{\prime}\right) i=1,2, \ldots m\right\}
\end{aligned}
$$

Where $K$ is associated with benefit criteria and $K^{\prime}$ is associated with cost criteria.

Step 5. Measure Euclidean distances of each alternative from the positive-ideal and negative-ideal solutions. The two separations for each alternative are respectively calculated as:

$$
\begin{aligned}
& D_{i}^{+}=\sqrt{\sum_{j=1}^{n}\left(V_{i j}-V_{j}^{+}\right)^{2}} ; \quad \mathrm{j}=1,2 \ldots \mathrm{n} ; \mathrm{i}=1,2 \ldots \mathrm{m} ; \\
& D_{i}^{-}=\sqrt{\sum_{j=1}^{n}\left(V_{i j}-V_{j}^{-}\right)^{2}} ; \quad \mathrm{j}=1,2 \ldots \mathrm{n} ; \mathrm{i}=1,2 \ldots \mathrm{m} ;
\end{aligned}
$$

Step 6. Calculate the relative closeness to the positive-ideal solution. The relative closeness to the positive-ideal solution can be defined as: 


$$
\mathrm{CC}_{\mathrm{i}}=\frac{D_{i}^{-}}{D_{i}^{+}+D^{-}} ; \mathrm{i}=1,2 \ldots \mathrm{m} ; \quad 0 \leq \mathrm{CC}_{\mathrm{i}} \leq 1 ;
$$

The higher the closeness means the better the rank.

\section{Data analysis and findings}

In this section we work out the TOPSIS method. The eight key issues obtained from Pareto analysis have been taken as alternatives A1, A2, A3, A4, A5, A6, A7, A8 and the five benefit criteria $\mathrm{C} 1, \mathrm{C} 2, \mathrm{C} 3, \mathrm{C} 4, \mathrm{C} 5$ as the evaluation criteria for these alternatives. The initial decision matrix and the normalized decision matrix with criteria weights are shown in Table 3 and Table 4 respectively.

\begin{tabular}{|c|r|r|r|r|r|}
\hline Alternatives & \multicolumn{1}{c|}{ C1 } & \multicolumn{1}{c|}{ C2 } & \multicolumn{1}{c|}{ C3 } & \multicolumn{1}{c|}{ C4 } & \multicolumn{1}{c|}{ C5 } \\
\hline A1 & 4.38 & 5.06 & 6 & 6 & 6.26 \\
\hline A2 & 8 & 6.4 & 5 & 6.01 & 7 \\
\hline A3 & 8.65 & 7 & 6 & 7 & 5.2 \\
\hline A4 & 6.1 & 6 & 7.06 & 6.28 & 6.13 \\
\hline A5 & 7 & 6.3 & 6.05 & 7.36 & 7 \\
\hline A6 & 6 & 3.26 & 3.41 & 3.4 & 5.18 \\
\hline A7 & 4.13 & 3 & 3.25 & 3.18 & 7.4 \\
\hline A8 & 3.38 & 3.21 & 4.03 & 3.3 & 5.26 \\
\hline
\end{tabular}

Table 3. The Decision matrix

\begin{tabular}{|c|r|r|r|r|r|}
\hline Alternatives & \multicolumn{1}{c|}{ C1 } & \multicolumn{1}{c|}{ C2 } & \multicolumn{1}{c|}{ C3 } & \multicolumn{1}{c|}{ C4 } & \multicolumn{1}{c|}{ C5 } \\
\hline A1 & 0.25 & 0.34 & 0.41 & 0.38 & 0.36 \\
\hline A2 & 0.46 & 0.43 & 0.34 & 0.38 & 0.41 \\
\hline A3 & 0.49 & 0.47 & 0.41 & 0.45 & 0.3 \\
\hline A4 & 0.35 & 0.41 & 0.48 & 0.4 & 0.36 \\
\hline A5 & 0.4 & 0.43 & 0.41 & 0.47 & 0.41 \\
\hline A6 & 0.34 & 0.22 & 0.23 & 0.21 & 0.3 \\
\hline A7 & 0.23 & 0.2 & 0.22 & 0.2 & 0.43 \\
\hline A8 & 0.19 & 0.21 & 0.27 & 0.21 & 0.3 \\
\hline Weights & 0.3 & 0.18 & 0.14 & 0.12 & 0.26 \\
\hline
\end{tabular}

Table 4.The normalized decision matrix

In the next step we compute the weighted normalized decision matrix which is shown in Table 5.

\begin{tabular}{|c|r|c|c|c|c|}
\hline Alternatives & \multicolumn{1}{c|}{ C1 } & C2 & C3 & C4 & C5 \\
\hline A1 & 0.075 & 0.061 & 0.057 & 0.045 & 0.093 \\
\hline A2 & 0.138 & 0.077 & 0.047 & 0.045 & 0.106 \\
\hline A3 & 0.147 & 0.084 & 0.057 & 0.054 & 0.078 \\
\hline A4 & 0.105 & 0.073 & 0.067 & 0.048 & 0.093 \\
\hline A5 & 0.12 & 0.077 & 0.057 & 0.056 & 0.106 \\
\hline A6 & 0.102 & 0.039 & 0.032 & 0.025 & 0.078 \\
\hline A7 & 0.069 & 0.036 & 0.03 & 0.024 & 0.111 \\
\hline A8 & 0.057 & 0.037 & 0.037 & 0.025 & 0.078 \\
\hline
\end{tabular}

Table 5. Weighted normalised decision matrix 
From Table 5 we determine the positive-ideal and negative-ideal solutions as-

$A^{+}=(0.147,0.084,0.067,0.056,0.111)$

$A^{-}=(0.057,0.036,0.030,0.024,0.078)$

Next we measure Euclidean distances of each alternative from the positive-ideal and negative-ideal solutions. The two separations for each alternative are represented by $D^{+}{ }_{i}, D_{i}^{-}$respectively. With the help of these distances we compute the closeness ratio as

$$
\mathrm{CC}_{\mathrm{i}}=\frac{D_{i}^{-}}{D_{i}^{+}+D_{i}^{-}} ; \mathrm{i}=1,2 \ldots \mathrm{m} ;
$$

We do ranking (Table 6 ) of the alternatives on the basis of the closeness ratio.

\begin{tabular}{|c|r|r|c|c|}
\hline Alternatives & \multicolumn{1}{|c|}{$\mathrm{D}^{+}{ }_{\mathrm{i}}$} & \multicolumn{1}{c|}{$\mathrm{D}_{\mathrm{i}}^{-}$} & $\mathrm{CC}_{\mathrm{i}}$ & Rank \\
\hline $\mathrm{A} 1$ & 0.0791 & 0.0484 & 0.3796 & 5 \\
\hline $\mathrm{A} 2$ & 0.026 & 0.0987 & 0.7914 & 1 \\
\hline $\mathrm{A} 3$ & 0.0345 & 0.1096 & 0.7605 & 2 \\
\hline $\mathrm{A} 4$ & 0.0476 & 0.0764 & 0.6161 & 4 \\
\hline $\mathrm{A} 5$ & 0.03 & 0.0904 & 0.7508 & 3 \\
\hline $\mathrm{A} 6$ & 0.0855 & 0.0451 & 0.3453 & 6 \\
\hline $\mathrm{A} 7$ & 0.1038 & 0.0351 & 0.2526 & 7 \\
\hline $\mathrm{A} 8$ & 0.1151 & 0.0071 & 0.0581 & 8 \\
\hline
\end{tabular}

Table 6. Alternatives on the basis of the closeness ratio

\section{Discussion}

From the above analysis the eight issues taken as alternatives were prioritized and ranked. In this section discussion has been done by taking the issues on the basis of ranking in descending order.

- Top management support: The commitment from top management is one of the most crucial issues in successful implementation of ERP. The approval of the project must be received from top management (Bingi, Sharma \& Godla 1999; Sumner, 1999). Without any support from top management in an organization mean fail in ERP implementation. The primary responsibility of Top management is to provide financial support and adequate resource that would lead to successful implementation of the system. The lack of financial support and adequate resources would ultimately lead to disruption of such implementation and the organizations have to incur huge loss. In other words top management support is required throughout the implementation. 
The support from top management not only mean of sanctioning fund and resource but to give time towards implementation process and to take care of human resource in particular.

- Properly defined goals and objectives: Properly defined goals and objective is considered as one of the important key issue in proper ERP implementation process. Goals should be measurable (Al-Mashari et al., 2003) and objective should be of doing industry best practice inving for the implementation process (Al-Mudimigh, Zairi \& Al-Mashari, 2001). The organization must carefully define what the need of such system is and find out what are the crucial business process the system will address (Bhatti, 2005).

- Project Management: Proper and good project management plays a vital role in successful implementation of ER Individuals and group of experts' expertise in the field of ERP are given responsibility to take the implementation project to success (Rosario, 2000). Project management should be maintained in methodical approach with proper user training and involvement of human resource participation. In a good project management the field should be properly established (Holland, Light \& Gibson, 1999; Rosario, 2000) and manageable (Rosario, 2000). In this respect the scope must be clearly defined and be limited. Project management can also be considered as managing properly the implementation task in terms of proper timeline and budget. Project management not only means planning all activities, but determining the project by its milestones, critical path and individual's responsibility (Nah \& Lau, 2001). It is being considered effective project management as the most important issue from the case study based on SMEs in china (Zhang, Lee, Zhang \& Banerjee, 2003). For Malaysian small and medium enterprises project management can be one of the issues towards successful ERP implementation (Noudoostbeni, Yasin \& Jenatabadi, 2009).

- Project Team Competence: Project team competence is one of the most cited critical issues towards successful implementation process of ER There is always need for sound, competent implementation team comprised of organization's best individuals in organizations. The team must possess necessary skill when doing the planning phase of implementation (Soh, Kien \& Tay-Yap, 2000). It is necessary for the team to have updated information technology as well as management knowledge like how to make the 
implementation process to run smoothly without disruption. When the team becomes expertise enough are able to give training to others (Bajwa, Garcia \& Mooney, 2004).

- Education and training: Education and training can be considered as the novel way to provide the method of providing knowledge of the ERP as far as SME is concerned. Excellent ERP system without adequate education and training can be considered as zero, it is the best way to let the staff and employees in an organization to know about ERP as because the top management including Directors, managers and staff may not be able to understand concept, operational necessity, cost and implementing process. The main objective of education and training is that the users must be able to know the business process behind the ERP implementation procedure ( $\mathrm{Al}$ -Mashari et al., 2003). From the published literature it has been found that many researchers agreed that proper education and training is one of the critical issues towards successful implementation of ERP (Bingi et al, 1999; Somers \& Nelson, 2001, 2004; Umble et al, 2003; Zhang, Lee \& Banerjee, 2002; Zhang, Lee, Huang, Zhang \& Huang, 2005; Zhou-Sivunen, 2005; Yusuf et al., 2006; Xia, Lok \& Yang, 2009).

- Change Management: Acceptance of change brought about by the implementation of ERP system is considered as the most cited key issue towards successful implementation of ER The concept of change management is the implementation team to be ready with change management program (Nah \& Lau, 2001). As part of change management program the users must be engaged in design and business process implementation and ERP, further to this end user training must be provided to help them (Bingi et al., 1999; Holland et al., 1999). Employees must be given proper training to let them understand the concept and how the system will change the business process.

- Proper package selection: From the past case studies irrespective of company's magnitude and from the published literature it has been found that proper package selection assumes a greater importance towards successful ERP implementation. That the clients must consider certain criteria while selecting the most appropriate selection of package for their organization including past record of ERP vendor's and their success stories, implementation assistance from vendor including the degree of customization of standard package (Sirigindi, 2000). However in case of 
selection of package some differences are observed between SME's and large organizations. SME's usually prefer those packages that require lesser implementation time, cost with lesser degree of customization (Everdingen, Hillergersberg \& Waarts, 2000).

- Effective Communication: Effective communication is critical towards successful implementation of ERP (Falkowski, Pedigo, Smith \& Swanson, 1998). Management of communication, education and reliance assumes a greater importance throughout the organization (Wee, 2000). With effective communication the promotion of project team and advertisement of project progress to the organization is expected (Holland et al., 1999). Regarding scope, objectives, activities, updating and change if any must be communicated properly to the employees in advance (Sumner, 1999).

\section{Conclusion}

The research presented here is solely devoted to the Indian small and medium scale enterprises (SME) in particular with the objective of identifying the issues that play a positive outcome in the implementation of ERP packages. The findings hold good for any organization in the small and medium scale sector which wishes to leverage the benefits of integration of business processes by implementing an ERP system in an organization. Literature shows many instances of ERP implementation which failed to deliver the business returns and in some cases the organizations incurred huge loss due to failed implementation. This is quite true in case of SME's because of their inherent peculiarities. The managers and users can be benefited from this study by identifying those ranked issues to make the implementation procedure smooth without any disruption. ERP vendors can take inputs from this study to change their implementation approach while targeting small scale enterprises. SMEs face pressures from various corners that include competition from global vendors, new regulatory compliance requirements that would come up every year requiring complying with and providing information to government agencies, needing to strengthen products and services, at the same time, physical expansion need to be taken care. With exposure to global economies, customers' preferences are changing drastically and accordingly, organizations need to enhance their products / services. Internally, within the organizations, they need to take care of risks due to employee churn, data security against competition, copyright protection, duplication of data, silos of applications and data etc. However there may be other issues that need to be explored. In the present economic scenario other issues that can have a significant effect on the decision of the SME's 
regarding purchase and implementation of an appropriate ERP package should be explored. There is scope to enhance this study by taking into consideration different types of industries and by extending number of respondents.

\section{References}

Aberdeen Report (2009). Measuring the ROI of ERP in SMB.

Al-Mashari, M., Al-Mudimigh, A. \& Zairi, M. (2003). Enterprise resource planning: A taxonomy of critical factors. European Journal of Operational Research, 146, 352364. http://dx.doi.org/10.1016/S0377-2217(02)00554-4

Al-Mudimigh, A., Zairi, M. \& Al-Mashari, M. (2001). ERP software implementation: An integrative framework. European Journal of Information Systems, 10, 216. http://dx.doi.org/10.1057/palgrave.ejis.3000406

Anexinet, R.B. (2006). Top 10 ERP implementation pitfalls. Retrieved February 11, 2010, from http://www.anexinet.com/pdfs/ERP top10pitfalls3-2006.pdf

Bajwa, D.S., Garcia, J.E. \& Mooney, T. (2004). An integrative framework for the assimilation of enterprise resource planning systems: Phases, antecedents, and outcomes. Journal of Computer Information Systems, 44, 81-90.

Bhatti, T.R. (2005). Critical success factors for the implementation of enterprise resource planning (ERP): Empirical validation. Proceedings of The Second International Conference on Innovation in Information Technology. Available from http://www.itinnovations.ae/iit005/proceedings/articles/F 4 IIT05 Bhatti.pdf

Bingi, P., Sharma, M.K. \& Godla, J. (1999). Critical issues affecting an ERP implementation. Information Systems Management, 7-14. http://dx.doi.org/10.1201/1078/43197.16.3.19990601/31310.2

Buonanno, G., Faverio, P., Pigni, F., Ravarini, A., Sciuto, D. \& Tagliavini, M. (2005). Factors affecting ERP system adoption: A comparative analysis between SMEs and large companies. Journal of Enterprise Information Management, 18(4), 384-426. http://dx.doi.org/10.1108/17410390510609572

Butler, T. \& Pyke, A. (2003). Examining the influence of ERP systems on firmspecific knowledge and core capabilities: a case study of SAP implementation and use. Proceedings of the Eleventh European Conference on Information Systems (Ciborra, C.U., Mercurio, R., de Marco. M., Martinez. M. \& Carignani, A. (Eds.), Naples, Italy. 
Chan, R. (1999). Knowledge management for implementing ERP in SME's. Paper presented at the 3rd Annual SAP Asia Pacific, Institute of Higher Learning Forum, and Singapore.

Chen, T.F. (2008). The creation and operation of knowledge based innovation networks in high tech SME's. Journal of Knowledge Management Practices, 9(4).

Deep A., Guttridge, P., Dani, S. \& Burns, N. (2008). Investigating factors affecting ERP selection in made to order SME sector. Journal of Manufacturing Technology Management, 19(4), 430-446. http://dx.doi.org/10.1108/17410380810869905

Ertugrul, I. \& Karakasoglu, N. (2007). Performance evaluation of Turkish cement firms with fuzzy analytic hierarchy process and TOPSIS methods. Expert Systems with Applications, 36(1), 702-715. http://dx.doi.org/10.1016/j.eswa.2007.10.014

Everdingen, Y., Hillergersberg, J. \& Waarts, E. (2000). ERP adoption by European midsize companies. Communications of ACM, 43(4), 27-31. http://dx.doi.org/10.1145/332051.332064

Ewusi-Mensah, K. (1997). Critical issues in abandoned information systems development projects. Communications of the ACM, 40(9), 74-80. http://dx.doi.org/10.1145/260750.260775

Falkowski, G., Pedigo, P., Smith, B. \& Swanson, D. (1998). A recipe for ERP success. Beyond Computing, 44-5.

Harvard, N. (2007). Statistics/Research on ERPs. Retrieved November 04, 2008, from http://erp.ittoolbox.com/groups/strategy-planning/erp Project: management/statisticsresearchonerps-1582241\#

Hayes, D.C., Hinton, J. \& Reck, J. (2001). Market reaction to ERP implementation announcements. Journal of Information Systems, 15(1), 3-18. http://dx.doi.org/10.2308/jis.2001.15.1.3

Helo, P. (2008). Expectation and reality in ERP implementation: Consultant and solution provider perspective. Journal of Industrial Management and Data System, 108(3), 1045-1069. http://dx.doi.org/10.1108/02635570810904604

Hinton, J.E., McEwen, R.A. \& Wier, B. (2002). The reaction of financial analysts to enterprise resource planning (ERP) implementation plans. Journal of Information Systems, 16(1), 31-40. http://dx.doi.org/10.2308/jis.2002.16.1.31 
Hitt, L.M., Wu, D.J. \& Zhou, X. (2002). Investment in enterprise resource planning: Business impact and productivity measures. Journal of Management Information Systems, 19(1), 71-98.

Holland, P., Light, B. \& Gibson, N. (1999). A critical success factors model for enterprise resource planning implementation. Proceedings of the 7th European Conference on Information Systems, 1, 273-297.

Hughes, M., Golden, W. \& Powell, P. (2003). Inter-Organizational ICT systems: The way to innovative practice for SMEs?. Journal of Small Business and Enterprise Development, 10(3), 277-286. http://dx.doi.org/10.1108/14626000310489754

Huin, S.F. (2004). Managing deployment of ERP systems in SMEs using multiagents. International Journal of Project Management, 22(6), 511-517. http://dx.doi.org/10.1016/j.ijproman.2003.12.005

Hwang, C.L., \& Yoon, K. (1981). Multiple attribute decision making: Methods and application. Verlag, Berlin: Springer. http://dx.doi.org/10.1007/978-3-642-48318-9

Ibrahim, A.M.S., Sharp, J.M. \& Syntetos, A.A. (2008). A framework for the implementation of ERP to improve business performance: A case study. In $Z$. Irani, S. Sahraoui, A. Ghoneim, J. Sharp, S. Ozkan, M. Ali \& S. Alshawi (Eds.), Proceedings of the European and Mediterranean Conference on Information Systems (EMCIS).

Jafari, S.M., Osman, M.R., Yusuf, R.M. \& Tang, S.H. (2006). ERP systems implementation in Malaysia: The importance of critical success factors. Engineering and Technology, 3, 125-131.

Kemppainen, I. (2004). Change management perspectives in an ERP implementation. Proceedings of the Twelfth European Conference on Information Systems (Leino, T., Saarinen, T. \& Klein, S. (Eds.), Turku, Finland.

Kimberling, E. (2006). 7 critical success factors to make your ERP or IT project successful Retrieved February 11, 2010, from http://it.toolbox.com/blogs/erp-roi/7criticalsuccess-factors-to-make-your-erp-or-it-project-successful-12058

Koh, S.C.L. \& Simpson, M. (2007). Could ERP creates competitive advantage for small business?. Benchmarking: An International Journal, 14(1), 59-76.

Kraemmergaard, P. \& Rose, J. (2002). Managerial competences for ERP journeys. Information Systems Frontiers, 4(2), 199. http://dx.doi.org/10.1023/A:1016054904008 
Laframboise, K. (2002). Business performance and enterprise resource planning. Proceedings of the Tenth European Conference on Information Systems (Wrycza S ed.), Gdansk, Poland.

Leung, C. (2008). ERP Implementation Failure Rate. Retrieved September 25, 2008, from http://wizebiz.ca/blog/2008/04/05/erp-implementation-failure-rate/

Lindley, J.T., Topping, S. \& Lindley, L. (2008). The hidden financial costs of ERP software. Managerial Finance, 34(2), 78-90. http://dx.doi.org/10.1108/03074350810841277

Loh, T.C. \& Koh, S.C.L. (2004). Critical elements for a successful enterprise resource planning implementation in small- and medium-sized enterprises. International Journal of Production Research, 42(17), 3433-3455. http://dx.doi.org/10.1080/00207540410001671679

Magnusson, J., Nilsson, A. \& Carlsson, F. (2004). Forecasting ERP implementation success - Towards a grounded framework. Proceedings of the Twelfth European Conference on Information Systems (Leino, T., Saarinen, T. \& Klein, S. (Eds.), Turku, Finland.

Mandal, P. \& Gunasekaran, A. (2002). Application of SAP R/3 in on-line inventory control. International Journal of Production Economics, 75, 47-55. http://dx.doi.org/10.1016/S0925-5273(01)00180-3

Moshabbaki, S.J.A. (2009). A trust based model for knowledge sharing in ERP Adopting Organization. Journal of Knowledge Management Practices, 10(1).

Nah, F.F. \& Lau, J.L. (2001). Critical success factors for successful implementation of enterprise systems. Business Process Management, 285-296.

Nandhakumar, J., Talvinen, J.M. \& Rossi, M. (2004). ERP revelations: The dynamics of contextual forces of ERP implementation. Proceedings of the Twelfth European Conference on Information Systems (Leino T, Saarinen T, Klein S eds.), Turku, Finland.

Noudoostbeni, A., Yasin, N.M. \& Jenatabadi, H.S. (2009). To investigate the Success and Failure Factors of ERP implementation within Malaysian Small and Medium Enterprises. Proceedings of the International Conference on Information Management and Engineering, ICIME '09, 3-5 April 2009, 157-160. 
Palaniswamy, R. \& Frank, T. (2000). Enhancing manufacturing performance with ERP systems. Information Systems Management, 43-55.

Proudlock, M. (1999). IT Adoption Strategies: Best Practice Guidelines for Professional SMEs,. Journal of Small Business and Enterprise Development, 6(3), 240-252. http://dx.doi.org/10.1108/EUM0000000006678

Rao, S.S. (2000). Enterprise resource planning: business needs and technologies. Industrial Management \& Data Systems, 100(2), 81-88. http://dx.doi.org/10.1108/02635570010286078

Rosario, J.G. (2000). On the leading edge: Critical success factors in ERP implementation projects'. Philippines: Business World.

Schubert, P. \& Leimstoll, U. (2004). Personalization of E-Commerce Applications in SME's: Conclusions from an Empirical Study in Switzerland. Journal of Electronic Commerce in Organizations, 2(3), July-Sept, 21-39. http://dx.doi.org/10.4018/jeco.2004070102

Schubert, P. (2003). Personalizing e-commerce applications in SME's. Proceedings of the Ninth Americas Conference on Information Systems (AMCIS).

Shang, S. \& Seddon, P.B. (2002). Assessing and managing the benefits of enterprise systems: The business manager's perspective. Information Systems Journal, 12(4), 271-299. http://dx.doi.org/10.1046/j.1365-2575.2002.00132.x

Siriginidi, S.R. (2000). Enterprise resource planning: Business needs and technologies. Industrial Management \& Data Systems, 100, 81. http://dx.doi.org/10.1108/02635570010286078

Soh, C., Kien, S.S. \& Tay-Yap, J. (2000). Cultural fits and misfits: is ERP a universal solution? Association for Computing Machinery. Communications of the ACM, 4347.

Somers, T.M. \& Nelson, K.G. (2001). The impact of critical success factors across the stages of enterprise resource planning implementations. Proceeding of the 34th Hawaii International Conference on System Sciences, Hawaii. http://dx.doi.org/10.1109/HICSS.2001.927129

Somers, T.M. \& Nelson, K.G. (2004). A taxonomy of players and activities across the project life cycle. Information \& Management, 41, 257-278. http://dx.doi.org/10.1016/S0378-7206(03)00023-5 
Stapleton, G. \& Rezak, C.J. (2004). Change management underpins a successful ERP implementation at Marathon Oil. Journal of Organization Excellence, 23(4), 15-21. http://dx.doi.org/10.1002/npr.20022

Sumner, M. (1999). Critical success factors in enterprise wide information management systems projects. Proceedings of the Americas Conference on Information Systems (AMCIS), 232-4.

Thomson, A. \& Gray, C. (1999). Determinants of Management Development in Small Business. Journal of Small Business and Enterprise Development, 6(2), 113-127. http://dx.doi.org/10.1108/EUM0000000006676

Umble, E.J., Haft, R.R. \& Umble, M.M. (2003). Enterprise resource planning: Implementation procedures and critical success factors. European Journal of Operational Research, 146, 241-257. http://dx.doi.org/10.1016/S03772217(02)00547-7

Upadhyay, P. \& Dan, P.K. (2008). An explorative study to identify the critical success factors for ERP implementation in Indian small and medium scale enterprises. Proceedings of the International Conference on Information Technology, 295-299. http://dx.doi.org/10.1109/ICIT.2008.66

Upadhyay, P., \& Dan, P.K. (2009). ERP in Indian SME's: A Post implementation study of the underlying critical success factors. International Journal of Management Innovation System, 1(2), E1.

Vogt, C. (2002). Intractable ERP a comprehensive analysis of failed enterpriseresources-planning projects. ACM SIGSOFT, 27(2), 62-68. http://dx.doi.org/10.1145/511152.511163

Wang, Y.M. \& Elhag, T.M.S. (2006). Fuzzy TOPSIS method based on alpha level sets with an application to bridge risk assessment. Expert Systems with Applications, 31, 309-319. http://dx.doi.org/10.1016/j.eswa.2005.09.040

Wee, S. (2000). Juggling toward ERP success: Keep key success factors high. ERP News, February, from http://www.erpnews.com/erpnews/erp904/02get.html.

Weightman, C. (2004). The top 10 ERP mistakes. Business Management, (February), 36-40. 
Westrup, C. \& Knight, F. (2000). Consultants and enterprise resource planning (ERP) systems. Proceedings of the Eighth European Conference on Information Systems (Hansen HR, Bichler M, Mahrer H eds.), Wien, Austria.

Woo, H.S. (2007). Critical success factors for implementing ERP: The case of a Chinese electronics manufacturer. Journal of Manufacturing Technology Management, 18(4), 431-442. http://dx.doi.org/10.1108/17410380710743798

Xia, Y., Lok, P. \& Yang, S. (2009). The ERP implementation of SME in China. Proceedings of the 6th International Conference on Service Systems and Service Management, 8-10 June, 135-140.

Yusuf, Y., Gunasekaran, A. \& Wu, C. (2006). Implementation of enterprise resource planning in China. Technovation, 26(12), 1324-1336. http://dx.doi.org/10.1016/j.technovation.2005.12.003

Zhang L, Lee M.K.O, Banerjee, P. (2002). Critical Success Factors of Enterprise Resource Planning Systems Implementation Success in China. Proceedings of the 36th Hawaii International Conference on System Sciences.

Zhang L., Lee M.K.O., Zhang, Z. \& Banerjee, P. (2003). Critical success factors of ERP implementation success in China. Proceedings of the $36^{\text {th }}$ Hawaii International Conference on System Sciences. http://dx.doi.org/10.1109/HICSS.2003.1174613

Zhang, Z., Lee, M., Huang, P., Zhang, L. \& Huang, X. (2005). A framework of ERP systems implementation success in China: An empirical study. International Journal of Production Economics, 98, 56-80. http://dx.doi.org/10.1016/j.ijpe.2004.09.004

Zhou-Sivunen, P. (2005). Organizational culture impact on ERP implementation in China. Swedish School of Economics and Business Administration. Retrieved June 22, 2008, from Academic OneFile Database. 